\title{
Schizophrenia relapse and the clinical usefulness of once-monthly aripiprazole depot injection
}

This article was published in the following Dove Press journal:

Neuropsychiatric Disease and Treatment

30 August 2014

Number of times this article has been viewed

\author{
Sheng-Min Wang' \\ Changsu Han ${ }^{2}$ \\ Soo-Jung Lee ${ }^{5}$ \\ Ashwin A Patkar ${ }^{3}$ \\ Prakash S Masand ${ }^{4}$ \\ Chi-Un Pae ${ }^{3,5}$
}

'International Health Care Center, Seoul St Mary's Hospital, The Catholic University of Korea, College of Medicine, Seoul, Republic of Korea; ${ }^{2}$ Department of Psychiatry, College of Medicine, Korea University, Seoul, Republic of Korea; ${ }^{3}$ Department of Psychiatry and Behavioral Sciences, Duke University Medical Center, Durham, NC, ${ }^{4}$ Global Medical Education, New York, NY, USA; ${ }^{5}$ Department of Psychiatry, Bucheon St Mary's Hospital, The Catholic University of Korea, College of Medicine, Seoul, Republic of Korea
Correspondence: Chi-Un Pae Department of Psychiatry, Bucheon St Mary's Hospital, The Catholic University of Korea College of Medicine, 2 Sosa-Dong, Wonmi-Gu, Bucheon 420-7/7, Gyeonggi-Do, Republic of Korea Tel +8232340 7067

Fax +8232340 2255

Email pae@catholic.ac.kr
Abstract: Improving medication adherence is critical to improving outcomes in patients with schizophrenia. A long-acting injectable (depot) antipsychotic is one of the most effective methods for improving treatment adherence and decreasing rehospitalization rates in patients with schizophrenia. Until recently, only three second-generation antipsychotics were available in a long-acting injectable formulation (risperidone, paliperidone, and olanzapine). In this respect, the emergence of long-acting aripiprazole injection (ALAI), approved by the US Food and Drug Administration for the treatment of schizophrenia in 2013, is timely. ALAI is a lyophilized powder of aripiprazole, and the aripiprazole molecule is unmodified. The initial and target dosage of ALAI is $400 \mathrm{mg}$ once monthly, but it could be reduced to $300 \mathrm{mg}$ if adverse reactions occur with $400 \mathrm{mg}$. When first administering ALAI, it is recommended to continue treatment with oral aripiprazole (10-20 mg/day) or another oral antipsychotic for 2 weeks in order to maintain therapeutic antipsychotic concentrations. The primary clearance route for ALAI is hepatic, ie, cytochrome P450 (CYP)2D6 and CYP3A4, so dose adjustment is required in poor CYP2D6 metabolizers. The efficacy of ALAI was demonstrated in three studies. A randomized controlled trial that formed the basis for approval of ALAI in the treatment of schizophrenia showed that ALAI significantly delayed time to impending relapse when compared with placebo $(P<0.0001, \log$-rank test). An open-label, mirror study demonstrated that total psychiatric hospitalization rates were significantly lower after switching from oral antipsychotics to ALAI. Another randomized controlled trial presented in poster form suggested that ALAI $400 \mathrm{mg}$ was comparable with oral aripiprazole $10-30 \mathrm{mg}$ in preventing relapse. ALAI was generally well tolerated during both short-term and long-term studies. Its tolerability profile, including extrapyramidal symptoms and clinically relevant metabolic parameters, was similar to placebo. However, insomnia, headache, anxiety, akathisia, weight gain, injection site pain, and tremor need clinical attention. These studies suggest that ALAI is a viable treatment option for patients with schizophrenia, but direct head-to-head comparisons between ALAI and other long-acting injectable antipsychotics are needed to elucidate its risk-benefit profile.

Keywords: aripiprazole, schizophrenia, depot, long-acting injectable, relapse, treatment

\section{Introduction}

Schizophrenia affects approximately $1 \%$ of the population, and is a devastating illness with a chronic impact on social and occupational functioning and activities of daily living. ${ }^{1,2}$ Therefore, maintenance treatment with antipsychotics is a core feature of its long-term management. ${ }^{3}$ Nonadherence to antipsychotic medication is one of the most important risk factors for relapse and hospitalization in patients receiving treatment for schizophrenia. ${ }^{4,5}$ A study showed that the median time to all-cause discontinuation of medication was less than 4 months for the majority of oral second-generation antipsychotics. ${ }^{6}$ Another study showed that more than $75 \%$ of patients with schizophrenia eventually became nonadherent within 2 years of being discharged 
from hospital. ${ }^{7}$ Nonadherence also largely contributes to an increased cost burden for patients. Up to $50 \%$ of direct medical costs of psychiatric hospitalization were attributed to nonadherence with antipsychotic medication. ${ }^{8,9}$

For these reasons, strategies to reduce hospitalization by improving medication adherence are becoming the focus of treatment in patients with schizophrenia. ${ }^{10,11}$ Depot antipsychotics are shown to be associated with a significantly lower risk of nonadherence and rehospitalization than oral antipsychotics. ${ }^{1,6}$ Since the introduction of a secondgeneration antipsychotic long-acting injection (risperidone) in 2003, only three second-generation antipsychotics have been available as a long-acting injectable formulation (risperidone, paliperidone, and olanzapine). ${ }^{12-14}$ In this respect, the emergence of a once-monthly aripiprazole depot injection or aripiprazole long-acting injection (ALAI) is a timely development. In 2013, ALAI was approved for the treatment of schizophrenia by the US Food and Drug Administration. ${ }^{15}$ The purpose of this paper is to provide a concise review regarding the clinical usefulness of once-monthly ALAI in patients with schizophrenia.

\section{Data search}

We conducted a data search on April 1, 2014, using the key terms "aripiprazole" with "depot", "once monthly", "longacting injection", and/or "long-acting injectable" in the following databases: PubMed, Embase/Medline, PsycINFO, and Cochrane Library. The studies searched were verified for publication in English peer-reviewed journals, but we did not utilize date constraints. Reference lists from the identified articles and reviews were also used to find additional studies.

Five published clinical trials were initially identified (Figure 1). One poster was found by searching scientific meetings for paper and poster presentations. To supplement these six studies, data obtained from the package information by Otsuka Pharmaceuticals were extracted online from http://www.fda.gov. The literature search and verification were handled first by one of the authors (SMW) and then independently reassessed by others (CUP and SJL). This paper aimed to provide a review of once-monthly aripiprazole depot injection in the treatment of patients with schizophrenia. Thus, all relevant studies meeting the aim of our review were selected based on consensus among the authors.

\section{General information}

A summary of general information concerning ALAI is provided in Table 1. ALAI is a lyophilized powder of aripiprazole, and the aripiprazole molecule is unmodified. ${ }^{16,17}$ The antipsychotic activity of ALAI is primarily from its parent drug, aripiprazole. ${ }^{17}$ Its major metabolite, dehydroaripiprazole, plays a minor role. The combination of partial agonism (agonism/antagonism) at dopamine $\mathrm{D}_{2}$ and serotonin $5-\mathrm{HT}_{1 \mathrm{~A}}$ receptors and antagonism at serotonin $5-\mathrm{HT}_{2 \mathrm{~A}}$ receptors is an important potential antipsychotic mechanism of aripiprazole. ${ }^{18-20}$ Following a single intramuscular dose of ALAI, the median time to peak plasma concentration was 5-7 days. Mean terminal elimination half-life of aripiprazole after every 4-weekly injection of ALAI $300 \mathrm{mg}$ and $400 \mathrm{mg}$ was 29.9 and 46.5 days, respectively. A study showed

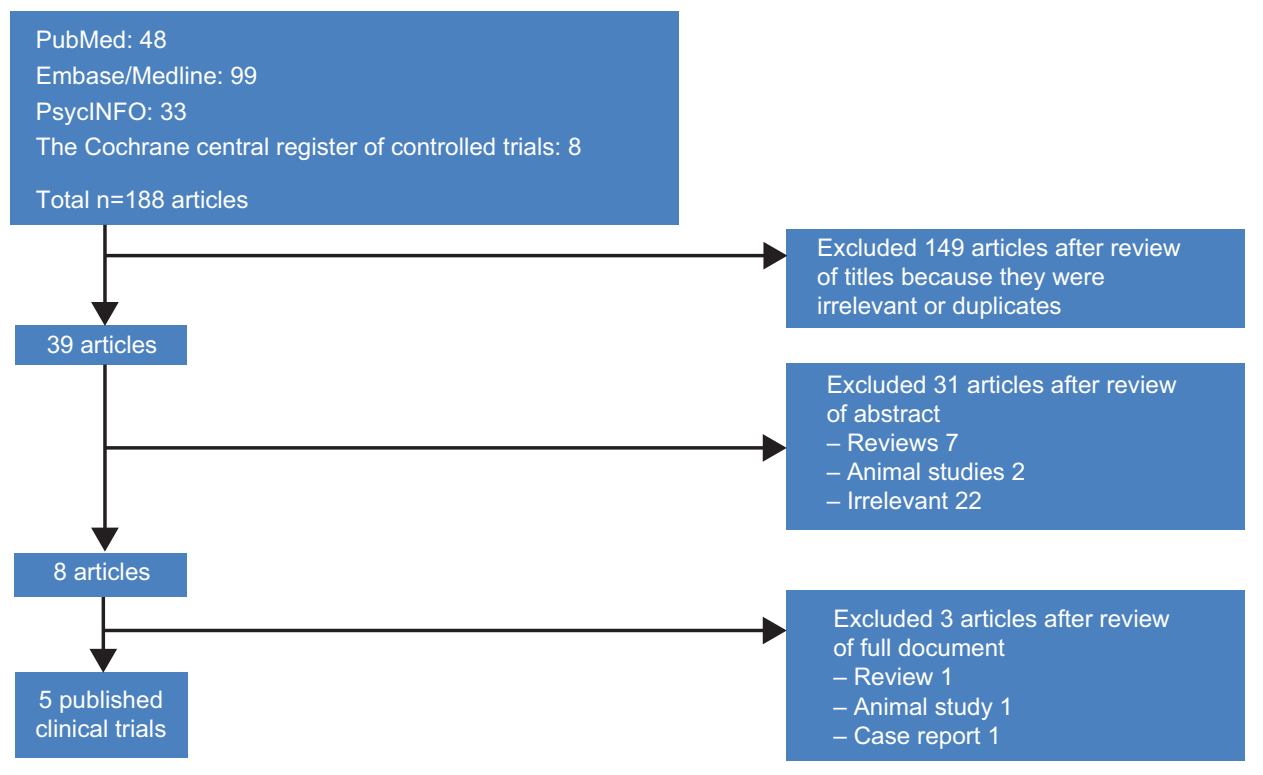

Figure I Flow chart for study selection. 
Table I General information on aripiprazole long-acting injection

\begin{tabular}{|c|c|}
\hline \multicolumn{2}{|l|}{ Pharmacokinetics } \\
\hline $\mathrm{T}_{\max }$ (days) & $5-7$ \\
\hline$t_{1 / 2}$ (days) & $29.9-46.5$ \\
\hline Time to steady state concentration & After dose 4 \\
\hline Major metabolism & Hepatic (CYP2D6 and CYP3A4) \\
\hline Needle gauge & 21 \\
\hline Approved injection site & Gluteal muscle \\
\hline \multicolumn{2}{|l|}{ Dosing and administration } \\
\hline Injection interval & 4 weeks \\
\hline Recommended initial and monthly dose & $400 \mathrm{mg}$ \\
\hline \multicolumn{2}{|l|}{ Dosage adjustments related to CYP metabolism } \\
\hline CYP2D6 poor metabolizers & $300 \mathrm{mg}$ \\
\hline CYP2D6 poor metabolizers + concomitant CYP3A4 inhibitors & $200 \mathrm{mg}$ \\
\hline \multicolumn{2}{|l|}{ Patient initially tolerant to ALAl $400 \mathrm{mg}$ taking concomitant } \\
\hline Strong CYP2D6 or CYP3A4 inhibitors & $300 \mathrm{mg}$ \\
\hline CYP2D6 and CYP3A4 inhibitors & $200 \mathrm{mg}$ \\
\hline CYP3A4 inducers & Avoid use \\
\hline \multicolumn{2}{|l|}{ Patient initially tolerant to ALAl $300 \mathrm{mg}$ taking concomitant } \\
\hline Strong CYP2D6 or CYP3A4 inhibitors & $200 \mathrm{mg}$ \\
\hline CYP2D6 and CYP3A4 inhibitors & $160 \mathrm{mg}$ \\
\hline CYP3A4 inducers & Avoid use \\
\hline \multicolumn{2}{|l|}{ Dosage adjustments for missed doses } \\
\hline \multicolumn{2}{|l|}{ Missed second or third doses } \\
\hline 4-5 weeks since last injection & Administer as soon as possible \\
\hline$>5$ weeks since last injection & Restart concomitant oral ARP for 14 days with the next injection \\
\hline \multicolumn{2}{|l|}{ Missed fourth or subsequent doses } \\
\hline 4-6 weeks since last injection & Administer as soon as possible \\
\hline$>6$ weeks since last injection & Restart concomitant oral ARP for I4 days with the next injection \\
\hline Pregnancy category & C \\
\hline Pediatric use $(<18$ years $)$ & Not established \\
\hline Geriatric use ( $>60$ years) & Not established \\
\hline
\end{tabular}

Note: Data used to compile this table are from..$^{16,17}$

Abbreviations: ARP, aripiprazole; CYP, cytochrome P450; $t_{1 / 2}$, terminal elimination half-life; $T_{\max }$, time to maximum plasma concentration of aripiprazole long-acting injection.

that aripiprazole and dehydro-aripiprazole concentrations increased proportionally with an increase in the dose of ALAI. ${ }^{16}$

Research showed that plasma levels of ALAI are consistent with those achieved by oral aripiprazole. ${ }^{16,17,21}$ A study simulated aripiprazole plasma concentration-time profiles based on the pharmacokinetic parameters for a single dose of ALAI and from previous oral aripiprazole steady-state studies. ${ }^{16}$ This simulation showed that minimum plasma drug concentrations during a dosing interval at steady-state $\left(\mathrm{C}_{\mathrm{ss}, \min }\right)$ for ALAI $300 \mathrm{mg}$ and $400 \mathrm{mg}$ corresponded to or was a little above the $\mathrm{C}_{\mathrm{ss} \text {, min }}$ for oral aripiprazole $10 \mathrm{mg} /$ day. The recommended initial and target dosage of ALAI is $400 \mathrm{mg}$ once a month, which could be reduced to $300 \mathrm{mg}$ once a month if adverse reactions occur with $400 \mathrm{mg} .{ }^{17}$ The appropriate site of injection is the gluteal muscle (intramuscular), and the injection should be performed by a health care professional. After the first ALAI, it is recommended to continue treatment with oral aripiprazole (10-20 mg/day) or another oral antipsychotic for 14 consecutive days in order to maintain therapeutic antipsychotic concentrations. The primary clearance route of ALAI is hepatic, ie, via cytochrome (CYP)2D6 and CYP3A4. Therefore, dosage adjustment of ALAI is required in patients who are poor CYP2D6 metabolizers, and also in patients taking concomitant CYP3A4 inhibitors and/or CYP2D6 inhibitors for more than 14 days. ${ }^{22}$ The injection schedule requires modification for missed doses.

\section{Clinical evidence}

Three studies investigated the efficacy of ALAI in the treatment of schizophrenia (Table 2). A placebo-controlled, randomized withdrawal maintenance study conducted in 2012 formed the basis of the approval of ALAI for the treatment of schizophrenia. ${ }^{21}$ This multicenter study compared the efficacy of ALAI with placebo in 403 patients (aged 18-60 years). Subjects enrolled had had a diagnosis of schizophrenia for at least 3 years according to the DSM-IV-TR (Diagnostic and Statistical Manual of 
Table 2 Summary of clinical trials of investigating efficacy of aripiprazole once monthly in patients with schizophrenia

\begin{tabular}{|c|c|c|c|c|c|c|}
\hline Study & Duration & Design & Daily dose (mg/4 weeks) & $n^{a}$ & Primary outcome & Results \\
\hline Kane et $\mathrm{al}^{21}$ & 52 weeks & $\mathrm{RCT}$ & $\begin{array}{l}\text { ALAI } \\
(300-400) \\
\text { Placebo IM }\end{array}$ & $\begin{array}{l}269 \\
134\end{array}$ & $\begin{array}{l}\text { Time to exacerbation } \\
\text { of psychotic symptoms/ } \\
\text { impending relapse }\end{array}$ & $\begin{array}{l}\text { ALAI > placebo IM } M^{* * *} \text { for } \\
\text { time to impending relapse }\end{array}$ \\
\hline Kane et $\mathrm{al}^{23}$ & 49 weeks $^{b}$ & $\begin{array}{l}\text { Open-label, } \\
\text { mirror image }\end{array}$ & $\begin{array}{l}\text { Oral antipsychotics } \\
\text { ALAl } \\
(300-400)\end{array}$ & $\begin{array}{l}183 \\
183\end{array}$ & Hospitalization rates & $\begin{array}{l}\text { Hospitalization rate ALAI } \\
<\text { oral antipsychotics*** }\end{array}$ \\
\hline $\begin{array}{l}\text { Fleischhacker } \\
\text { et } \mathrm{al}^{24}\end{array}$ & 52 weeks & RCT & $\begin{array}{l}\text { ALAI } \\
(300-400) \\
\text { Oral ARP } \\
(10-30 \mathrm{mg} / \text { day }) \\
\text { ALAl } \\
(25-50)\end{array}$ & $\begin{array}{l}265 \\
266 \\
131\end{array}$ & $\begin{array}{l}\text { Rate of exacerbation } \\
\text { of psychotic symptoms/ } \\
\text { impending relapse }\end{array}$ & $\begin{array}{l}\text { ALAI }(300-400)=\text { oral ARP } \\
\text { ALAI }(300-400) \text { and oral } \\
\text { ARP }>\text { ALAI }(25-50)^{* *} \text { in } \\
\text { relapse rate }\end{array}$ \\
\hline
\end{tabular}

Notes: ${ }^{\mathrm{a}}$ Total number of intent-to-treat patients; ${ }^{\mathrm{2}} 24$ weeks of treatment with oral antipsychotics, one week of stabilization, and 24 weeks of ALAl; ${ }^{\mathrm{c}} \mathrm{standard}$ of care $* * P<0.01 ; * * * P<0.001$

Abbreviations: ALAI, aripiprazole long-acting injection; ARP, aripiprazole; RCT, randomized controlled trial; IM, intramuscular route.

Mental Disorders, Fourth Edition, Text Revision). All patients had a history of symptom exacerbation or relapse when not receiving antipsychotic treatment. Patients initially entered the oral conversion phase (phase 1) to cross-titrate their antipsychotics to oral aripiprazole monotherapy over 4 weeks. After stabilizing their symptoms using open-label oral aripiprazole monotherapy for 8 weeks (phase 2), patients meeting the criteria for stabilization then received open-label ALAI (phase 3). Thereafter, patients who remained consistently stable for more than 3 months with ALAI entered the double-blind phase (phase 4) and were randomized in a 2:1 ratio to intramuscular ALAI $400 \mathrm{mg}$ (or $300 \mathrm{mg}$ if not tolerant of $400 \mathrm{mg}$ ) or placebo (ALAI, $\mathrm{n}=269$; placebo, $n=134$ ). The primary outcome measure was time to exacerbation of psychotic symptoms/impending relapse, defined as meeting any or all of the following predefined criteria during the double-blind phase (phase 4):

- Clinical worsening - Clinical Global ImpressionImprovement (CGI-I) score of $\geq 5$ plus an increase of score to $>4$ on any of the core Positive and Negative Syndrome Scale (PANSS) items (conceptual disorganization, hallucinatory behavior, suspiciousness, or unusual thought content) with an absolute score of $\geq 2$ on that specific item or an increase $>4$ on these PANSS items and an absolute increase of $\geq 4$ on the combined score of these items since randomization

- Aggravation of psychotic symptoms - hospitalization

- Risk of suicide - Clinical Global Impression-Severity of Suicidality (CGI-SS) score of 4 (severely suicidal) or 5 (attempted suicide) on part 1 or a score of 6 (much worse) or 7 (very much worse) on part 2

- Violent behavior - clinically significant self-injury, injuring others, or damaging the property of others.
The mean patient age in the ALAI and placebo groups was 40.1 years and 41.7 years, respectively. The result showed that time to impending relapse was significantly delayed in the ALAI group when compared with the placebo group in both the interim and final analyses $(P<0.0001, \log$-rank test). Time to study discontinuation, for reasons other than study termination, from the double-blind phase was also significantly longer with ALAI than with placebo $(P \leq 0.001$, log-rank test). Since the efficacy of ALAI was demonstrated by the preplanned interim analysis, the study was terminated early. Moreover, the rate of relapse was significantly lower in the ALAI group (9.6\%) when compared with the placebo group (36.8\%; hazard ratio $4.72,95 \%$ confidence interval [CI] 2.81-7.94), with a calculated number needed to treat for relapse of 4 (CI 3-5). ${ }^{22}$ Clinical Global Impression-Severity (CGI-S) and PANSS total scores were maintained with ALAI but worsened significantly with placebo.

The second study used an open-label, mirror image design to investigate hospitalization rates in patients with schizophrenia treated retrospectively with oral antipsychotics followed by prospective treatment with ALAI in a naturalistic community setting. ${ }^{23} \mathrm{~A}$ total of 183 patients with schizophrenia, aged 18-65 years, participated in the study. In the first phase of the study, patients were treated with oral standardof-care antipsychotics (retrospective data) for 6 months. After 4 weeks of stabilization, the same patients were treated with ALAI $400 \mathrm{mg}$ (prospective data) for 6 months. The primary endpoint was a comparison of the proportion of patients hospitalized in the latter 3 months of the retrospective oral antipsychotic treatment period and those hospitalized during the latter 3 months of the prospective ALAI 400 treatment period (months 4-6). The results showed that total psychiatric hospitalization rates were significantly lower after switching 
to ALAI (months 4-6) when compared with the 3-month retrospective treatment period (months -4 to -1 ) when the same patients were receiving oral antipsychotics $(6.6 \%$ versus $28.1 \%, P<0.0001)$. Total psychiatric hospitalization rates were also lower in whole prospective 6 months after patients were switched to ALAI (hospitalization rate for months $0-6$ was $14.2 \%$ ) than whole retrospective 6 months while they were on oral antipsychotics (hospitalization rate for months -7 to $-1,41.5 \%, P<0.0001$ ).

The third study, which was reported as a poster, is a double-blind, randomized comparison of ALAI with oral aripiprazole using a noninferiority design. ${ }^{24}$ After an oral conversion phase and a stabilization phase, patients were randomized to ALAI $400 \mathrm{mg}$ (with an option to decrease to $300 \mathrm{mg}$ ), oral aripiprazole (10-30 mg/day), and ALAI $50 \mathrm{mg}$ (with an option to decrease to $25 \mathrm{mg}$ ). ALAI $50 \mathrm{mg}$ is a subtherapeutic dosage and its purpose was for assay sensitivity. The results showed no significant difference in the relapse rate between ALAI $400 \mathrm{mg}$ (7.1\%) and oral aripiprazole $(7.8 \%)$. Both treatment arms were significantly superior to ALAI $50 \mathrm{mg}(21.8 \% ; P<0.001) .{ }^{25}$ In addition, time to impending relapse was also significantly delayed in the ALAI $400 \mathrm{mg}$ group when compared with the ALAI $50 \mathrm{mg}$ group (hazard ratio 3.2, CI 1.8-5.5; $P<0.0001$, logrank test), but was similar between the ALAI $400 \mathrm{mg}$ group and the oral aripiprazole group (hazard ratio 1.0, CI 0.6-1.8; $P=0.99$, log-rank test). ${ }^{22}$

\section{Safety and tolerability}

Four studies assessed the safety and tolerability of ALAI in patients with schizophrenia. ${ }^{16,21,26,27}$ However, a long-term study by Fleischhacker et $\mathrm{al}^{26}$ was an extension of the pivotal clinical trial by Kane et al. ${ }^{21}$ Thus, the study by Fleischhacker et al generally contained all the safety and tolerability data reported in the study by Kane et al. The long-term study by Fleischhacker et al evaluated the safety and tolerability of ALAI throughout four study phases: oral conversion (phase 1, 4-6 weeks); oral stabilization (phase 2, 4-12 weeks); stabilization of ALAI with coadministration of oral aripiprazole (phase 3, 12-36 weeks); and a 52-week, randomized double-blind, maintenance phase (phase 4, ALAI versus placebo). ${ }^{26}$ Adverse events $(>5 \%)$ in any phase were insomnia, headache, anxiety, akathisia, weight gain, injection site pain, and tremor. The incidence of extrapyramidal symptoms was similar in all phases, and no significant differences between the ALAI $400 \mathrm{mg}$ group and the placebo group were observed in any of the three extrapyramidal symptom scales (Abnormal Involuntary Movement Scale, Simpson
Angus Scale, and Barnes Akathisia Rating Scale). ${ }^{21,26}$ No changes in clinically relevant metabolic parameters were noted across the study phases. Moreover, the adverse event rate for the ALAI $400 \mathrm{mg}$ group was comparable with that in the placebo group in the double-blind phase.

A multicenter, open-label, parallel-arm study investigated the safety and tolerability of ALAI $200 \mathrm{mg}$ ( $\mathrm{n=10}$ ), $300 \mathrm{mg}$ $(\mathrm{n}=15)$, and $400 \mathrm{mg}(\mathrm{n}=14) .{ }^{16}$ Most treatment-emergent adverse events were classified as mild or moderate in intensity. Four patients in the ALAI $400 \mathrm{mg}$ group reported injection site pain as a common treatment-emergent adverse event, but there were no reports of injection site pain in the ALAI $200 \mathrm{mg}$ and $300 \mathrm{mg}$ groups. Tremor, upper respiratory infection, musculoskeletal symptoms, sedation, rash, headache, and weight gain were also more common in the ALAI $400 \mathrm{mg}$ group than in the ALAI $200 \mathrm{mg}$ and $300 \mathrm{mg}$ groups. Although the incidence of treatment-emergent adverse events tended to increase with the dosage of ALAI, the sample size was too small to evaluate its clinical significance. Four patients (10.3\%) discontinued treatment due to treatment-emergent adverse events, but none receiving ALAI $400 \mathrm{mg}$ withdrew from the study. Three subjects in the ALAI $300 \mathrm{mg}$ group discontinued because of drug dependence, worsening of psychosis, and worsening of schizophrenia symptoms, and one patient in the ALAI $200 \mathrm{mg}$ group discontinued due to worsening of psychosis.

The third study investigated the safety and tolerability of a single dose of ALAI $400 \mathrm{mg}$ in patients with schizophrenia stabilized on oral atypical antipsychotics other than aripiprazole (not included in Table 3 ). ${ }^{27}$ In this open-label multicenter trial, 60 patients received ALAI $400 \mathrm{mg}$ while taking oral olanzapine $(n=3)$, quetiapine $(n=28)$, risperidone $(n=24)$, or ziprasidone $(n=5)$. The most common treatmentemergent adverse events were injection site pain and toothache (4/60 for both, $6.7 \%)$, but overall the treatment was well tolerated. This study showed that the safety profile in patients receiving concomitant ALAI and oral antipsychotics other than aripiprazole was comparable with that reported previously in patients receiving concomitant ALAI and oral aripiprazole. ${ }^{21}$ Psychotic symptoms, ie, secondary endpoint measures evaluated using PANSS total scores, CGI-S, and CGI-I scores, remained stable during the study. The mean baseline and mean changes at endpoint were 64.5 and -3.7 , respectively, for PANSS total scores and 3.3 and -0.1 for CGI-S scores. The mean CGI-I score at week 1 was 3.85 and at week 4 was 3.58 . This study suggests that when switching from existing oral antipsychotics to ALAI, clinicians could directly switch to ALAI without the trouble of stabilizing with oral aripiprazole. 
Table 3 Safety and tolerability of aripiprazole once-monthly in patients with schizophrenia

\begin{tabular}{|c|c|c|c|c|c|c|}
\hline \multicolumn{3}{|l|}{ Fleischhacker et $\mathrm{al}^{26}$} & \multicolumn{4}{|l|}{ Mallikaarjun et al' ${ }^{16}$} \\
\hline \multirow[t]{2}{*}{ Adverse event } & \multicolumn{2}{|l|}{ Group } & \multirow[t]{2}{*}{ Adverse event } & \multicolumn{3}{|l|}{ Group } \\
\hline & $\begin{array}{l}\text { ALAI } 400(\%) \\
(n=269)\end{array}$ & $\begin{array}{l}\text { Placebo (\%) } \\
(n=134)\end{array}$ & & $\begin{array}{l}\text { ALAl } 200(\%) \\
(n=10)\end{array}$ & $\begin{array}{l}\text { ALAI } 300(\%) \\
(n=15)\end{array}$ & $\begin{array}{l}\text { ALAI } 400(\%) \\
(n=14)\end{array}$ \\
\hline Insomnia & $27(10.0)$ & $12(9.0)$ & Injection site pain & $0(0.0)$ & $0(0.0)$ & $4(28.6)$ \\
\hline Weight gain & $26(9.7)$ & I3 (9.7) & Tremor & $0(0.0)$ & I (6.7) & $3(2 \mid .4)$ \\
\hline Anxiety & $16(5.9)$ & $10(7.5)$ & URTI & I $(10.0)$ & $2(13.3)$ & $4(28.6)$ \\
\hline Headache & $16(5.9)$ & $7(5.2)$ & Vomiting & $0(0.0)$ & $2(13.3)$ & $2(14.3)$ \\
\hline Tremor & $16(5.9)$ & $2(1.5)$ & Muscular symptoms & $0(0.0)$ & $0(0.0)$ & $4(28.6)$ \\
\hline Akathisia & $15(5.9)$ & $8(6.0)$ & Sedation & $0(0.0)$ & $0(0.0)$ & $2(14.3)$ \\
\hline Nasopharyngitis & $10(3.7)$ & $7(5.2)$ & Rash & $0(0.0)$ & $0(0.0)$ & $2(14.3)$ \\
\hline Worsening psychosis & $8(3.0)$ & $9(6.7)$ & Headache & $2(20.0)$ & $0(0.0)$ & $2(14.3)$ \\
\hline Injection site pain & $8(3.0)$ & $5(3.7)$ & Weight gain & I (I0.0) & $2(13.3)$ & $3(21.4)$ \\
\hline
\end{tabular}

Abbreviations: ALAI, aripiprazole long-acting injection; URTI, upper respiratory tract infection including nasopharyngitis.

\section{Expert opinion}

ALAI is a viable treatment option for patients with schizophrenia. The beneficial effects of ALAI in preventing relapse of schizophrenia are supported by three clinical studies. One randomized controlled trial demonstrated superior efficacy of ALAI over placebo for preventing relapse in patients with schizophrenia. ${ }^{21}$ One open-label, mirror image study also showed that ALAI was superior to oral standard-of-care antipsychotics in decreasing hospitalization rates. ${ }^{23}$ Another randomized controlled trial, which has been presented only as a poster at the time of writing, shows that ALAI is as effective as oral aripiprazole in preventing relapse of schizophrenia. ${ }^{24}$

The safety and tolerability of ALAI has been well documented by four clinical trials. The pivotal clinical trial by Kane et al and a long-term safety study, which was an expansion of the pivotal trial, showed that ALAI was as well tolerated as placebo. ${ }^{21,26}$ An open-label, parallel-arm study demonstrated the safety and tolerability of three different doses of ALAI, ie, $200 \mathrm{mg}, 300 \mathrm{mg}$, and $400 \mathrm{mg} .{ }^{16}$ Moreover, the safety profile in patients receiving ALAI and oral antipsychotics other than aripiprazole concomitantly was comparable with that in patients receiving ALAI and oral aripiprazole concomitantly. ${ }^{27}$ Psychotic symptoms assessed by PANSS total scores, CGI-S scores, and CGI-I scores, also remained stable during the same study, suggesting that clinicians could directly switch to ALAI without the trouble of stabilizing with oral aripiprazole. However, insomnia, headache, anxiety, akathisia, weight gain, injection site pain, and tremor need close monitoring when administering ALAI.

Despite the availability of these studies, more research is needed to clarify important issues. For example, clinical trials comparing the efficacy, tolerability, and safety of ALAI with that of other long-acting injectable antipsychotics are required to elaborate its risk-benefit profile. In addition, studies are also needed to confirm its efficacy and safety in pediatric and geriatric patients with schizophrenia.

\section{Disclosure}

The authors report no conflicts of interest in this work.

\section{References}

1. Tiihonen J, Haukka J, Taylor M, Haddad PM, Patel MX, Korhonen P. A nationwide cohort study of oral and depot antipsychotics after first hospitalization for schizophrenia. Am J Psychiatry. 2011;168:603-609.

2. Goreishizadeh M, Mohagheghi A, Farhang S, Alizadeh L. Psychosocial disabilities in patients with schizophrenia. Iran J Public Health. 2012;41:116-121.

3. Leucht S, Tardy M, Komossa K, Heres S, Kissling W, Davis JM. Maintenance treatment with antipsychotic drugs for schizophrenia. Cochrane Database Syst Rev. 2012;5:CD008016.

4. Novick D, Haro JM, Suarez D, Perez V, Dittmann RW, Haddad PM. Predictors and clinical consequences of non-adherence with antipsychotic medication in the outpatient treatment of schizophrenia. Psychiatry Res. 2010;176:109-113.

5. Acosta FJ, Hernandez JL, Pereira J, Herrera J, Rodriguez CJ. Medication adherence in schizophrenia. World J Psychiatry. 2012;2:74-82.

6. Bitter I, Katona L, Zambori J, et al. Comparative effectiveness of depot and oral second generation antipsychotic drugs in schizophrenia: a nationwide study in Hungary. Eur Neuropsychopharmacol. 2013;23:1383-1390.

7. Weiden P, Rapkin B, Zygmunt A, Mott T, Goldman D, Frances A. Postdischarge medication compliance of inpatients converted from an oral to a depot neuroleptic regimen. Psychiatr Serv. 1995;46:1049-1054.

8. Weiden PJ, Olfson M. Cost of relapse in schizophrenia. Schizophr Bull. 1995;21:419-429.

9. Lafeuille MH, Gravel J, Lefebvre P, et al. Patterns of relapse and associated cost burden in schizophrenia patients receiving atypical antipsychotics. J Med Econ. 2013;16:1290-1299.

10. Kane JM. Improving treatment adherence in patients with schizophrenia. J Clin Psychiatry. 2011;72:e28.

11. Marcus SC, Olfson M. Outpatient antipsychotic treatment and inpatient costs of schizophrenia. Schizophr Bull. 2008;34:173-180.

12. Love RC, Conley RJ. Long-acting risperidone injection. Am J Health Syst Pharm. 2004;61:1792-1800.

13. Nussbaum AM, Stroup TS. Paliperidone palmitate for schizophrenia. Cochrane Database Syst Rev. 2012;6:CD008296.

14. Frampton JE. Olanzapine long-acting injection: a review of its use in the treatment of schizophrenia. Drugs. 2010;70:2289-2313. 
15. Motiwala FB, Siscoe KS, El-Mallakh RS. Review of depot aripiprazole for schizophrenia. Patient Prefer Adherence. 2013;7:1181-1187.

16. Mallikaarjun S, Kane JM, Bricmont P, et al. Pharmacokinetics, tolerability and safety of aripiprazole once-monthly in adult schizophrenia: an open-label, parallel-arm, multiple-dose study. Schizophr Res. 2013;150:281-288.

17. Otsuka Pharmaceutical Co Ltd. Abilify Maintena ${ }^{\mathrm{TM}}$ (aripiprazole) extended release injectable suspension, package insert. Tokyo, Japan: Otsuka Pharmaceutical Co Ltd. Available from: http://www.otsuka-us. com/Products/Documents/Abilify.M.PI.pdf. Accessed April 23, 2014

18. Pae CU. A review of the safety and tolerability of aripiprazole. Expert Opin Drug Saf. 2009;8:373-386.

19. Burris KD, Molski TF, Xu C, et al. Aripiprazole, a novel antipsychotic, is a high-affinity partial agonist at human dopamine $\mathrm{D} 2$ receptors. J Pharmacol Exp Ther. 2002;302:381-389.

20. Jordan S, Koprivica V, Chen R, Tottori K, Kikuchi T, Altar CA. The antipsychotic aripiprazole is a potent, partial agonist at the human 5-HT ${ }_{1 \mathrm{~A}}$ receptor. Eur J Pharmacol. 2002;441:137-140.

21. Kane JM, Sanchez R, Perry PP, et al. Aripiprazole intramuscular depot as maintenance treatment in patients with schizophrenia: a 52-week, multicenter, randomized, double-blind, placebo-controlled study. J Clin Psychiatry. 2012;73:617-624.
22. Citrome L. New second-generation long-acting injectable antipsychotics for the treatment of schizophrenia. Expert Rev Neurother. 2013; 13:767-783.

23. Kane JM, Sanchez R, Zhao J, et al. Hospitalisation rates in patients switched from oral anti-psychotics to aripiprazole once-monthly for the management of schizophrenia. J Med Econ. 2013;16:917-925.

24. Fleischhacker WW, Sanchez R, et al. Aripiprazole once-monthly for treatment of schizophrenia: double-blind, randomised, non-inferiority study. Br J Psychiatry. In press 2014.

25. Rauch AS, Fleischhacker WW. Long-acting injectable formulations of new-generation antipsychotics: a review from a clinical perspective. CNS Drugs. 2013;27:637-652.

26. Fleischhacker WW, Sanchez R, Johnson B, et al. Long-term safety and tolerability of aripiprazole once-monthly in maintenance treatment of patients with schizophrenia. Int Clin Psychopharmacol. 2013;28:171-176.

27. Potkin SG, Raoufinia A, Mallikaarjun S, et al. Safety and tolerability of once monthly aripiprazole treatment initiation in adults with schizophrenia stabilized on selected atypical oral antipsychotics other than aripiprazole. Curr Med Res Opin. 2013;29:1241-1251.
Neuropsychiatric Disease and Treatment

\section{Publish your work in this journal}

Neuropsychiatric Disease and Treatment is an international, peerreviewed journal of clinical therapeutics and pharmacology focusing on concise rapid reporting of clinical or pre-clinical studies on a range of neuropsychiatric and neurological disorders. This journal is indexed on PubMed Central, the 'PsycINFO' database and CAS,

\section{Dovepress}

and is the official journal of The International Neuropsychiatric Association (INA). The manuscript management system is completely online and includes a very quick and fair peer-review system, which is all easy to use. Visit http://www.dovepress.com/testimonials.php to read real quotes from published authors. 